\title{
Detection of wheat hardness based on a laser-generated ultrasonic signal
}

\author{
Fan Chao
}

College of the Information Science and Engineering, Henan University of Technology, Zhengzhou, China, 450001

Received: 06.07.2017

\begin{abstract}
Hardness is an important index for wheat quality, which determines its usage, price and wheat-processing techniques. Therefore accurate measurements of the hardness of kernels is a key problem for assessing wheat quality. In this work we develop a new method for testing the hardness basing on a laser-induced ultrasonic signal. We describe the measurement principles, as well as sampling and preprocessing of ultrasonic signals. The acoustic signal is analyzed both in the time and frequency domains, using fast Fourier, discrete cosine (DCT) and wavelet (WT) transforms. The main eight parameters whose correlation indices surpass the threshold of 0.8 are selected as feature characteristic parameters of the hardness. They include a waveform index T6, a pulse factor T7, sub-band energy ratios $\mathrm{SER}_{1}-$ $\mathrm{SER}_{3}$, a sum of the DCT magnitudes, and two wavelet parameters, WTF1 and WTF2. A testing model of the hardness is built basing on a standard extreme learning machine (ELM) algorithm and using all of these feature parameters as an input. A number of experiments have been performed on twenty wheat varieties with different hardness indices. The results show that the maximal relative measurement error and the mean relative error are approximately equal to $-3 \%$ and $1 \%$, respectively. As a result, our method of measuring the wheat hardness, which is based on combination of laser ultrasonic waves and ELM, is feasible and accurate enough.
\end{abstract}

Keywords: wheat hardness, laser ultrasonic, spectral analysis, extreme learning machine

PACS: 2010:78.20.hc

UDC: 535.8

\section{Introduction}

Wheat is one of the most important cereals in the world, of which total planning areas, production amounts and trade volumes are the largest among the grains. To estimate the quality of wheat, its hardness is used as an important index determining flour extraction rate, flour and milling qualities, processing energy consuming and ultimate usage [1]. A number of methods have been used to measure the wheat hardness. These are a press method [2], grinding and anti-crashing index methods [3], an imaging processing method [4, 5] and some others. Although their principles are mostly simple, there are many limitations. For instance, the appropriate experimental procedures are often complex, the testing time is long and kernels are often damaged. This does not meet the requirements of real-time and non-destructive measurements.

To solve the problem, a near-infrared spectroscopy and artificial neural networks have been used to predict the hardness and the other quality parameters of wheat [6-8], although the corresponding measurement accuracy is easily affected by the moisture of kernels. In the recent years, acoustic methods have been put forward. So, D. Massie et al. have used an improved constant-speed millstone to get acoustic signal when the kernels are grinded [9], along with a 
hardness model of wheat. However, kernels are damaged in this process. In 2005, H. W. Yang has designed an acoustic-emitting device to measure the wheat hardness, where the kernels fell down freely and affected a steel plan [10]. Then a highly sensitive microphone is used to detect a sound signal. After some feature parameters are extracted, one can develop a testing model based on a back-propagation neural network, to forecast the hardness. Later, A. Marzec et al. have obtained the acoustic signals by crushing kernels [11]. According to experimental results, one observes significant correlation between the signal and the wheat hardness.

Although the methods mentioned above can efficiently test the wheat hardness, the measurement accuracy is greatly affected by a background noise. To improve the signal-to-noise ratio (SNR), some extra processing should be adopted, which usually limits a real-time feature of the methods. Hence, finding a quick, accurate, non-destructive and cheap method for testing the hardness is still an urgent need. In the present work we put forward a new method for testing the kernel hardness, which is based on the erosion effect of laser ultrasonic signal. First, the ultrasonic signal from the wheat is obtained using laser erosion. Then the characteristic parameters of longitudinal ultrasonic waves are extracted both in the time and frequency domains. Finally, to measure the wheat hardness, we introduce these parameters into a testing model based on an extreme learning machine (ELM).

\section{Measurement principles of wheat hardness basing on laser-induced ultrasonic signal}

When a surface of kernel is exposed to pulsed-laser light, mutational temperature and stress fields are formed in a rim surface zone of a grain as a result of energy absorption. This excites ultrasonic waves, as illustrated schematically in Fig. 1. A pulsed-laser beam (the wavelength $\lambda=1024 \mathrm{~nm}$, the power $2 \mathrm{~W}$, the repetition frequency $10-50 \mathrm{~Hz}$ and the duration time $10 \mathrm{~ns}$ ) is divided into two beams by a splitting mirror. A reflected beam is used as a synchronous-detection signal of an oscilloscope, and a transmitted light is converged on a wheat surface after weakening by an attenuator. The transmitted-light intensity is adjusted so that to surpass the erosion threshold of wheat. Therefore the grain surface is expanded and evaporated, thus exciting a strong ultrasonic signal. This signal is received near the grain surface by a detector (a capacitive ultrasonic detector with the sensitivity $2.0 \mathrm{mV} / \mathrm{Pa}$, the SNR $90 \mathrm{~dB}$, the dynamic range $40-170 \mathrm{~dB}$ and the response frequency $50-200 \mathrm{kHz})$. Then it is amplified and displayed on an oscilloscope [12, 13].

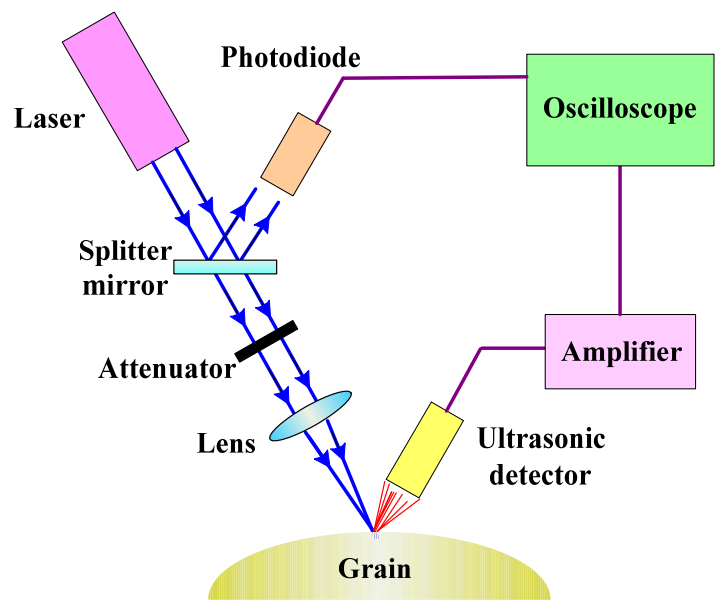

Fig. 1. Schematic diagram of our hardness-testing method. 
There are many hypotheses about the force induced by a pulsed laser during interaction of the laser beam with the material [14]. To find the acting force in analytical form, we proceed from assumption of a Gaussian-like beam of a single-pulse laser. In addition, during energy exchange between the laser wave and the kernel, the heat-exchange effect is primary, while the effects of radiation and convection can be ignored [15]. Since the light absorption occurs only inside a superficial kernel layer, the light energy can be absorbed quickly within a very thin surface of the kernel, whenever the laser axis is arranged vertically. Then we suppose that the light energy absorbed by wheat is totally transformed into thermal energy.

According to the law of energy conservation, the entropy of wheat increases quickly on the surface, which gives rise to local temperature increment and volume expansion. We use the column coordinates, considering the Gauss characteristics of the pulsed laser and the kernel shape. The equation of heat conduction can be expressed as follow:

$$
-\rho c \frac{\partial T(r, z, t)}{\partial t}+\frac{1}{r} \frac{\partial}{\partial r}\left(r k \frac{\partial T(r, z, t)}{\partial r}\right)+\frac{\partial}{\partial z}\left(k \frac{\partial T(r, z, t)}{\partial z}\right)=I(r, z, t),
$$

where $T(r, z, t)$ represents the temperature distribution at a time $t, I(r, z, t)$ denotes the powerdensity distribution of the incident pulsed-laser light, and $\rho, c$ and $k$ are respectively the parameters of hardness, heat capacity and thermal diffusivity of wheat. With increasing temperature, the local region on the surface expands and a transient displacement is excited. The corresponding displacement $U(r, z, t)$ can be written based on the equation of thermoelastic effect:

$$
(\lambda+2 \mu) \nabla(\nabla \cdot U)-\mu \Delta \times \nabla \times U-\alpha(3 \lambda+2 \mu) \nabla T(r, z, t)=\rho \frac{\partial^{2} U}{\partial t^{2}},
$$

where $\lambda$ and $\mu$ represent the Lame constants, and $\rho$ and $a$ are respectively the hardness and the thermal expansion coefficient of wheat.

According to Eqs. (1) and (2), the ultrasonic displacement $U(r, z, t)$ excited by the pulsedlaser erosion is linked with the hardness $\rho$. Then the hardness parameter of the kernel can be derived after the changes in the ultrasonic displacement have been measured.

\section{Feature extraction for the acoustic signal}

\subsection{Signal acquisition and pre-processing}

Considering a great diversity of wheat and a random position of radiation point on the kernel, one can predict a large difference in the ultrasonic intensities. Fig. 2a shows the signals taken from two wheat varieties with different hardnesses. Here we deal with the factor that affects the measurement accuracy seriously. To improve the sampled signal, two microphones with different preamplifiers are used in our experiments. Their amplifications are equal to 1 and $10 \mathrm{~V} / \mathrm{Pa}$, and their frequency response ranges are the same, $100 \mathrm{kHz}$. The two microphones are mounted parallel along the reflecting direction of laser light, and the distance from the kernel surface to the microphones is about $20-25 \mathrm{~mm}$. When the kernel is irradiated by the pulsed laser, the excited signal could be sampled by these two microphones at the same time. After the sampled signals are filtered and amplified, the noise whose frequency is lower than $60 \mathrm{~Hz}$ is eliminated and the signal power is increased. After that, the improved sound signal is converted by a 16-bit A/D card. According to the Shannon's law, the sampled frequency then amounts to $200 \mathrm{kHz}$.

Let the signal sampled by the microphone with the amplification of $1 \mathrm{~V} / \mathrm{Pa}$ be denoted as $f_{1}(x)$, and the signal sampled by the other detector as $f_{2}(x)$, with $x$ representing a sampled point. First one has to calculate the number of saturation points for these two signals. If this number is not larger than ten for the function $f_{2}(x)$, we adopt it as a final ultrasonic signal. Otherwise, the 


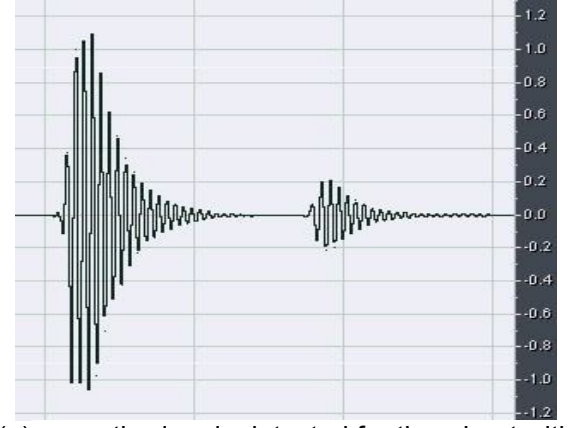

(a) acoustic signals detected for the wheat with different hardnesses

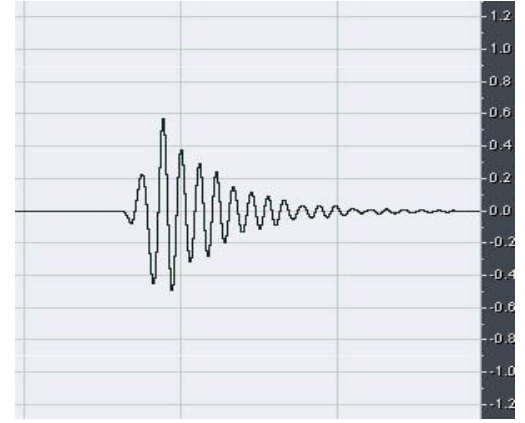

(b) pre-processed ultrasonic signal

Fig. 2. Acoustic signals detected in case of wheat with different hardness parameters (a) and pre-processed ultrasonic signal (b).

signal $f_{1}(x)$ is used. After the sound signal is pre-processed and selected by the above procedures, the signal excited by the pulsed laser is obtained (see Fig. 2b).

\subsection{Feature extraction}

The laser-induced ultrasonic signal carries a lot of information about the hardness of wheat. Analyzing it and extracting properly characteristic parameters of the signal is a key for any hardness testing. The features of the signal can be divided into two groups, time- and frequencydomain ones.

\subsubsection{Feature extraction in the time domain}

In the time domain, the character of signal is described mainly by the amplitude, the wavelength and the period. Then one can calculate the feature parameters in the time domain, which include the absolute amplitude average $\mathrm{T} 1$, the energy $\mathrm{T} 2$, the power $\mathrm{T} 3$, the mean square root of the amplitude $\mathrm{T} 4$, the zero-passage ratio $\mathrm{T} 5$, the waveform index $\mathrm{T} 6$, and the pulse factor $\mathrm{T} 7$. Definitions of these parameters are readily available in the literature [13]. The correlation between each of the parameters and the wheat hardness can also be calculated. Then the factors with the coefficients surpassing a threshold of, say, 0.8 can be selected as the main characteristics of the wheat hardness. They have turned out to be the waveform index T6 and the pulse factor T7. The relationships of these feature parameters and the hardness of wheat are illustrated in Fig. 3. Although the slope changes for $\mathrm{T} 6$ and $\mathrm{T} 7$ are different, the both parameters are correlated positively to the hardness, whereas the tendencies of variations are similar.
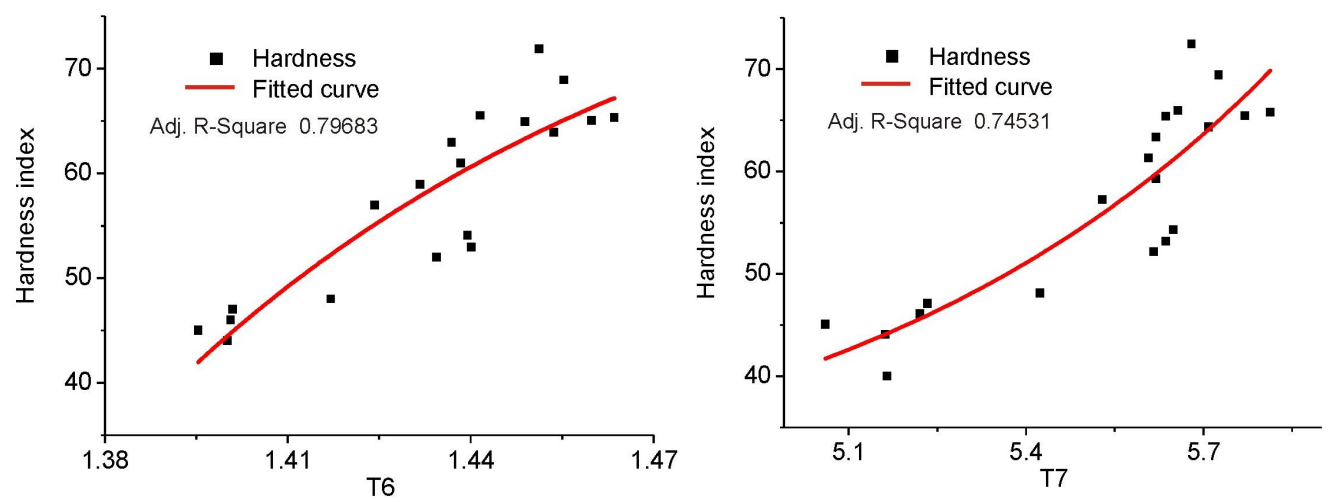

Fig. 3. Relationships of $T 6$ and $T 7$ parameters with the wheat hardness (see the text). 


\subsubsection{Feature extraction in the frequency domain}

The spectrum and the power distribution of any signal can be described in the frequency domain. Some of the corresponding parameters can have a close link with the hardness and, therefore, can be selected as the main feature parameters. In our experiments, we have used the fast Fourier transform (FFT), the discrete cosine transform (DCT) and the wavelet transform (WT) to extract the characteristics of signal.

\section{(1) Feature extraction based on the FFT}

FFT of a signal is defined as follows:

$$
\mathrm{X}(\mathrm{k})=\sum_{x=0}^{N-1} f(x) e^{-\frac{2 \pi x k}{N}} .
$$

where $N$ is the length of signal. In our experiments, the response frequency of the microphone ranges from 0 to $100 \mathrm{kHz}$. Then the frequency spectrum is divided into sub-bands of the length $1000 \mathrm{~Hz}: f_{1}, f_{2}, \ldots, f_{i}, \ldots, f_{100}$. Then one can calculate the energy of the sub-band $f_{M}$ :

$$
\mathrm{E}\left(\mathrm{f}_{M}\right)=\sum_{j=(M-1) \times 1000}^{M \times 1000}\left|X\left(k_{M j}\right)\right|^{2} .
$$

The sum of the spectral energies $S\left(X_{i}\right)$ can be computed as

$$
\mathrm{S}\left(\mathrm{X}_{i}\right)=\sum_{i=1}^{100} E\left(f_{i}\right) \text {. }
$$

Denoting the ratio of $E\left(f_{M}\right)$ and $S\left(X_{i}\right)$ as a sub-band energy ratio (SER), we obtain

$$
\mathrm{SER}=\mathrm{E}\left(\mathrm{f}_{\mathrm{M}}\right) / \mathrm{S}\left(\mathrm{X}_{\mathrm{i}}\right) \text {. }
$$

Twenty different wheat varieties have been used in our experiments and 1000 kernels have been selected as testing samples for each of the variety. Application of the FFT to the signals and calculation of the SER parameters have revealed that the SERs corresponding to three different sub-bands are fairly correlated with the hardness. These are the sub-bands $8-9,9-10$ and $14-15 \mathrm{kHz}$, of which SERs are denoted as $\mathrm{SER}_{1}, \mathrm{SER}_{2}$ and $\mathrm{SER}_{3}$. Dependences of the wheat hardness on the those parameters are depicted in Fig. 4.

(2) Feature extraction based on the DCT

DCT is similar to discrete Fourier transform, although its energy is more concentrated, which can make the energy focus in a few sub-bands. Thus, the transform error is less if one processes signals with poor initial data and strong correlations. The 1D DCT may be written as

$$
\mathrm{X}(\mathrm{k})=\sqrt{\frac{2}{N}} C(k) \sum_{x=0}^{N-1} f(x) \cos \left[\frac{(2 x+1) k \pi}{2 N}\right], k=0,1, \cdots, N-1,
$$

where

$$
\mathrm{C}(\mathrm{k})=\left\{\begin{array}{c}
1 / \sqrt{2}, \quad k=0 \\
1, \quad k=1, \cdots, N-1
\end{array} .\right.
$$

The DCT processing of the signals includes the follows stages:

(i) calculating $8192 \mathrm{DCT}$ points for every ultrasonic signal and obtaining a serial $A_{1 \times 8192}$;

(ii) computing the square of $A$ and obtaining a new sequence $B_{1 \times 8192}$;

(iii) calculating the sum of all the $B$ elements, which is denoted as $P$, and then dividing the sequence $B$ by $P$, with the result given by a serial $C_{1 \times 8192}$; 
(iv) calculating the average of the $C$ for each point and for all of these kernels (it is supposed that there are $L$ kernels in every sample); the latter parameter is used as the DCT magnitude for this point; then a series $D_{1 \times 8192}$ is obtained, which is regarded as the DCT for a given sample.
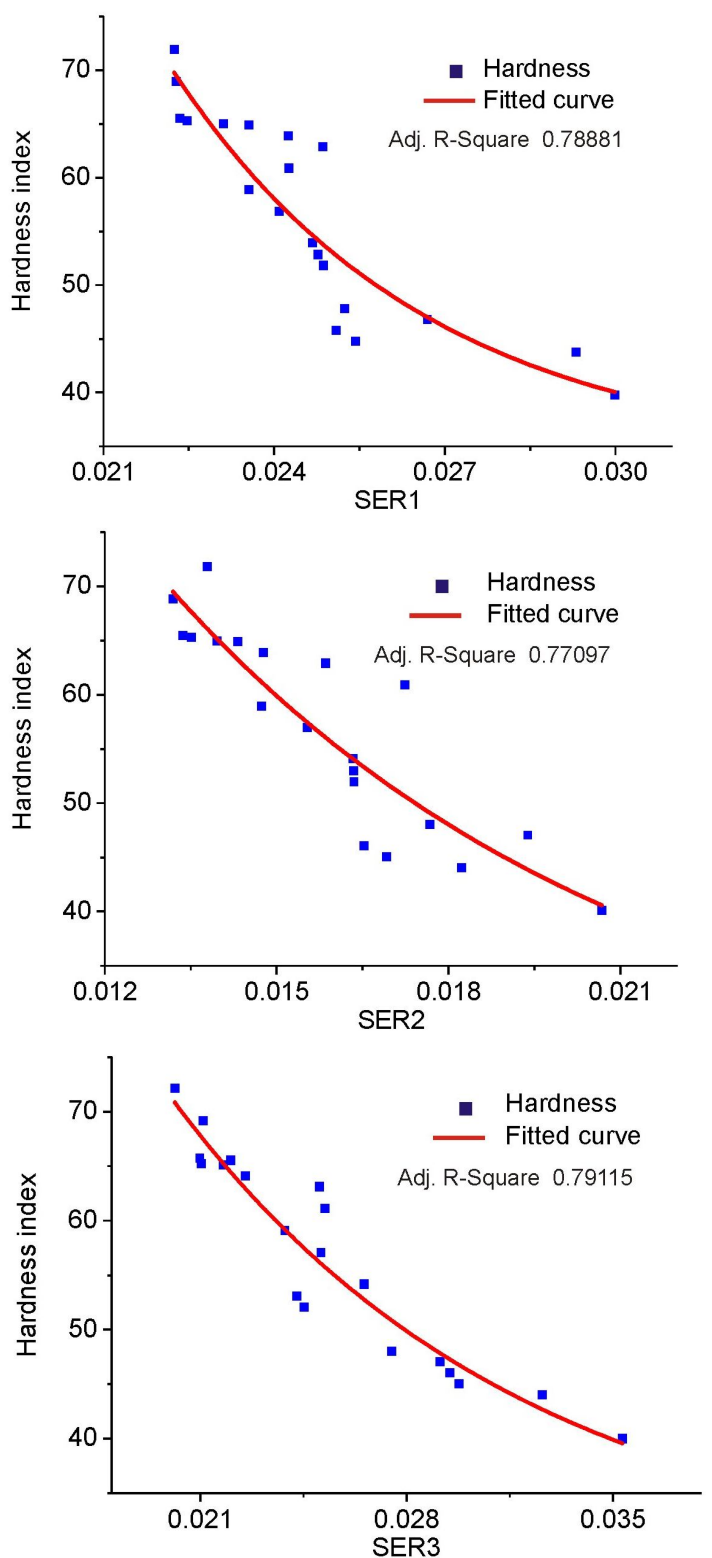

Fig. 4. Relationships of $\mathrm{SER}_{1}, \mathrm{SER}_{2}$ and $\mathrm{SER}_{3}$ parameters with the wheat hardness (see the text).

We have found experimentally that different DCT spectra can be observed for different hardnesses at the points ranging from 2386 to 2995. As an example, Fig. 5 shows the DCT spectra for the two wheat samples with the hardnesses equal to 47.0 and 65.7. One can use the sum of the DCT magnitudes corresponding to the above range as a characteristic parameter in the frequency domain. It is denoted as DT. The relationship between DT and the hardness is illustrated in Fig. 6. As seen from Fig. 6, the DT value increases with increasing hardness. 


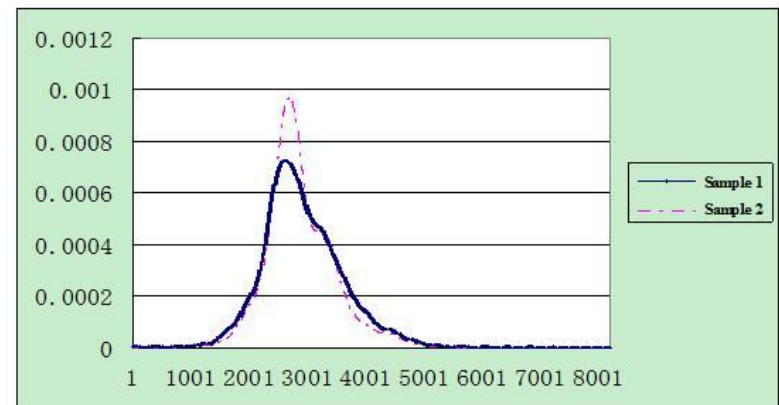

Fig. 5. Probability distributions of serials $D_{1 \times 8192}$ referred to samples 1 and 2 . The hardnesses of samples 1 and 2 are equal to 47.0 and 65.7 , respectively.

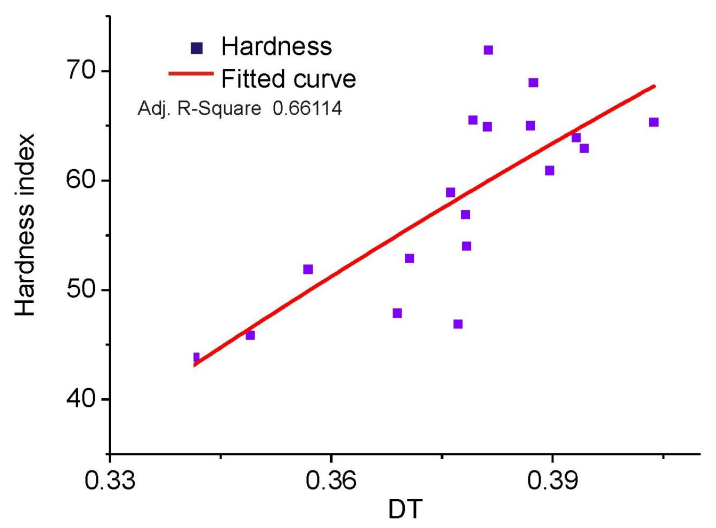

Fig. 6. Relationship between DT parameter and the wheat hardness.

\section{(3) Feature extraction based on the WT}

WT, which is derived from a short-time Fourier transform, supplies an observation window that can be adjusted automatically with changing frequency. The observation window with high time resolution and low frequency is more adopted for the high-frequency part of signal, which makes the WT promising for analyzing local signals both in the time and frequency domains. A sampled ultrasonic signal is decomposed into three layers with the WT, basing on a standard wavelet function $d_{\mathrm{b} 5}$. Then four coefficient serials $d_{1}, d_{2}, d_{3}$ and $a_{3}$ are obtained (see Fig. 7).

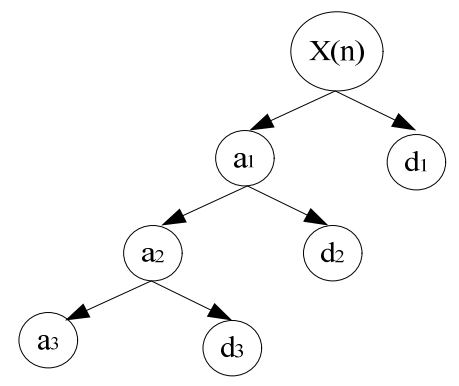

Fig. 7. Diagram that explains WT-decomposition of a signal.

The ultrasonic signal has been sampled and four wavelet serials have been obtained for each kernel. Then the averages of each of the serials have been calculated for all of the kernels contained in every sample. As a result, four new sequences have been obtained, which are denoted as $D_{1}, D_{2}, D_{3}$ and $A_{3}$. These four serials have been compared for the two wheat varieties with 
different hardnesses. As seen form Fig. 8, the sub-bands from 16 to 20 for $D_{3}$ and $A_{3}$ are evidently different. This can be used to distinguish the hardness of wheat. We have calculated the quadratic sums of these two parts and denoted them as $\mathrm{WTF}_{1}$ and $\mathrm{WTF}_{2}$. Our experimental results indicate that the latter parameters correlate strongly with the wheat hardness (see Fig. 9). Hence, they are also taken as the feature characteristics of the laser-induced ultrasonic signal in the frequency domain.

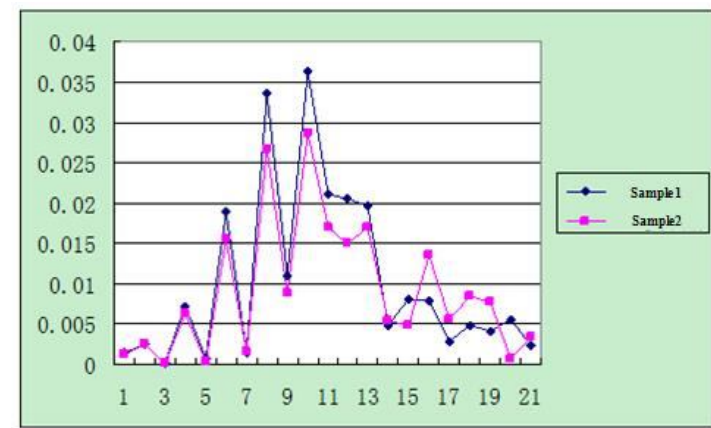

(a) distribution of $D_{1}$

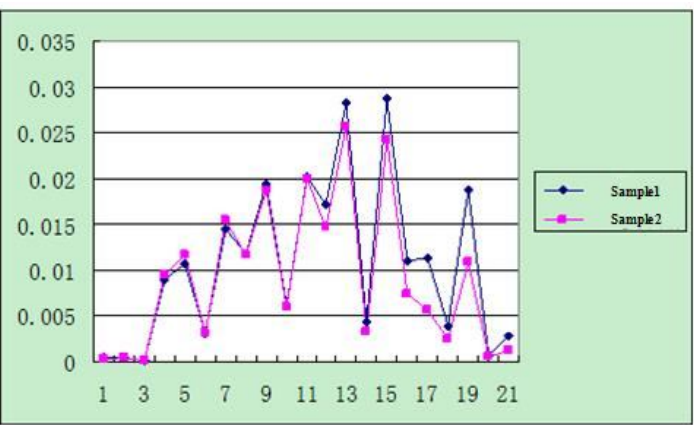

(b) distribution of $D_{2}$

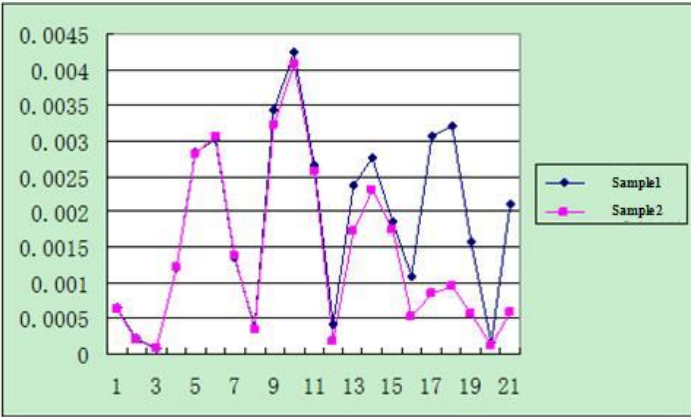

(c) distribution of $D_{3}$

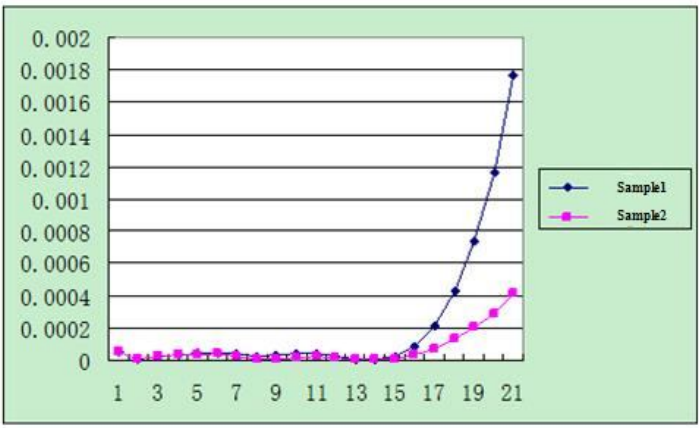

(d) distribution of $A_{3}$

Fig. 8. Comparison of WT coefficients for samples 1 and 2. The hardnesses of samples 1 and 2 are equal to 47.0 and 65.7 , respectively. 
According to the analysis performed above, one can extract a number of feature parameters in both the time and frequency domains to measure the hardness of the wheat accurately. This is based on the sampled ultrasonic signals, which are described by the two time-domain parameters (the waveform index T6 and the pulse factor T7) and the six frequency-domain parameters ( $\mathrm{SER}_{1}$, $\mathrm{SER}_{2}, \mathrm{SER}_{3}, \mathrm{DT}, \mathrm{WTF}_{1}$ and $\mathrm{WTF}_{2}$ ). Issuing from these points, a hardness-measurement model has been built that involves all of the above parameters.
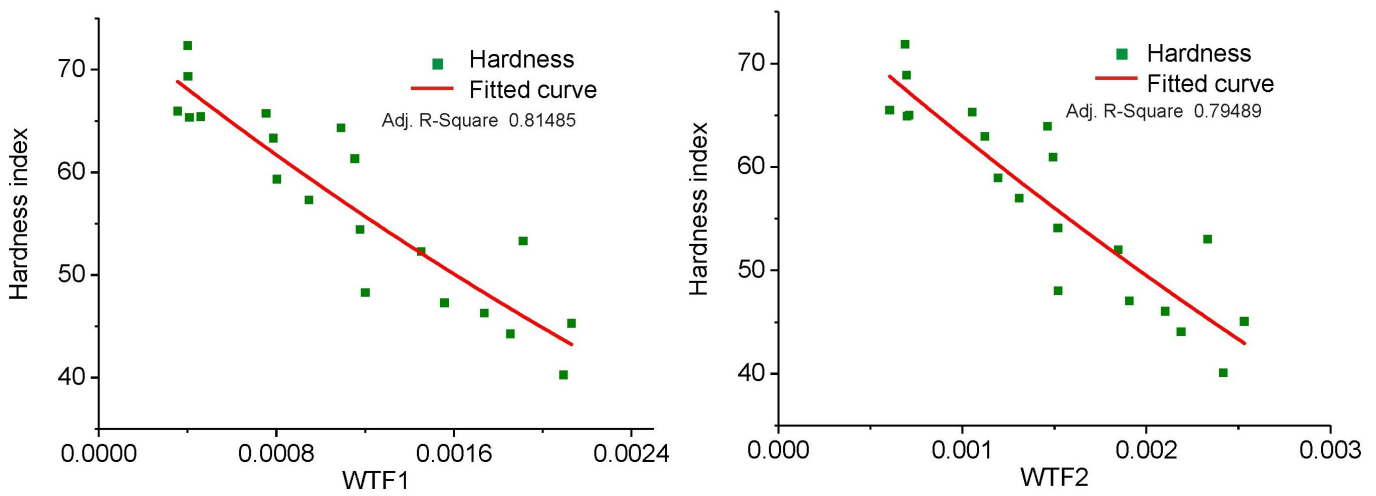

Fig. 9. Relationships of WTF1 and WTF2 parameters with the wheat hardness.

\section{Determining the hardness from ELM-based testing model}

There are many methods for building a testing model, e.g. polynomial fitting, a back-propagation neural network and a support vector machine. Although the polynomial-fitting method is easy, its error remains large for a single-order polynomial. To increase the fitting accuracy, higher-order polynomials should be used, which in fact violates a real-time feasibility of the method. In case of the back-propagation neural network, many parameters of a net should be set initially. Moreover, the problems of low efficiency and local optimum are often faced. In order to overcome this drawback, one can use the support vector-machine method. However, the parameters of support vector machine should be adjusted well to get the optimum model, which often costs a lot of time. In recent years, the ELM has been put forward to solve the problem. Within this approach, only node numbers of a hidden layer should be set initially. At the same time, the input nodes' weights and the nodes' thresholds for the hidden layer need not be adjusted at the stage when the model is being developed. As a consequence, a single-optimum model can finally be obtained, thus implying fast learning speed and good generalization ability of the ELM.

The ELM is a kind of novel single-hidden layer feed-forward neural network, of which structural diagram is shown in Fig. 10. Here $x_{1} \ldots x_{N}$ represent the input nodes, $h_{i}$ is the weight relating the input node and the $i$-th node of the hidden layer, $\beta_{i}$ the weight relating the $i$-th node of the hidden layer and the output node, $b_{i}$ the bias of the $i$-th node of the hidden layer, and $t_{j}$ the output for the hardness that corresponds to the sample $j$. In our experiments, the extracted feature parameters for each kernel in the training sample have been used as the inputs and the corresponding hardness index has been taken as the output for the ELM. Thus, the input order of the data has no influence on the precision of the model. In other words, it does not matter which of the kernels is studied first. Therefore, exchanging the orders of the elements has also no influence on the solution of our model.

To establish the testing model of the wheat hardness, twenty wheat varieties have been used and 100 kernels have been selected from each variety, to form a training sample. Hence, there are 2000 kernels in total in the training sample. The ultrasonic signals have been obtained for each of 


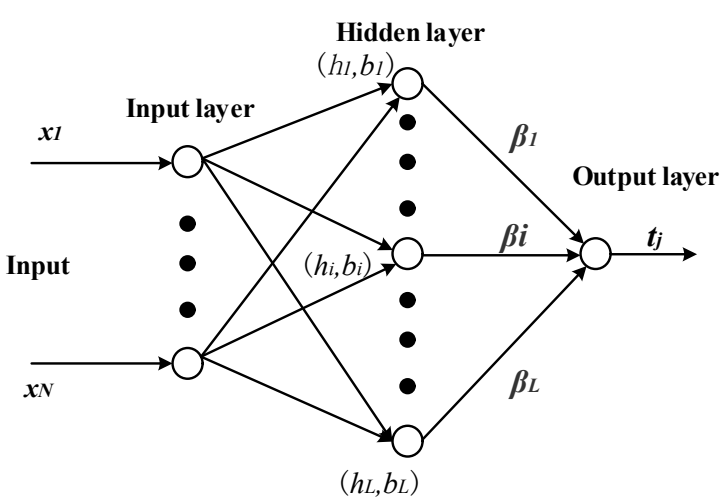

Fig. 10. Structural diagram of the ELM.

the kernels and the corresponding feature parameters have been extracted. Then the feature parameters and the hardness index can be used respectively as the input and the output of the model. In other terms, there are eight nodes in the input layer and one node in the output layer. The node number of the implicit layer can vary from 13 to 20 .

To establish the testing model of the wheat hardness, twenty wheat varieties have been used and 100

kernels have been selected from each variety, to form a training sample. Hence, there are 2000 kernels in total in the training sample. The ultrasonic signals have been obtained for each of the kernels and the corresponding feature parameters have been extracted. Then the feature parameters and the hardness index can be used respectively as the input and the output of the model. In other terms, there are eight nodes in the input layer and one node in the output layer. The node number of the implicit layer can vary from 13 to 20 .

The experimental results have testified that, when the node number of the hidden layer is equal to 17 , the performance of hardness testing becomes the best. Therefore the optimal structure of our ELM model is $8-17-1$. Then 20 kernels are randomly selected from each wheat variety to construct the testing sample. After extracting the characteristics for each kernel, the feature parameters are introduced into the model and the hardness index is calculated automatically. For each wheat variety, the hardness indices for all of the 20 kernels predicted by the testing model are averaged and these averages are used as final experimental results for this variety. The hardness indices for all of the 20 wheat varieties have been forecasted in this manner, as illustrated in Fig. 11. Our results demonstrate that the maximal relative error is as small as $-3 \%$, whereas the average measurement error is still less, being close to $1 \%$. This implies that our method for measuring the wheat hardness based on the laser ultrasonic signal is feasible. Moreover, the testing accuracy appears to be better, if compared with the other hardness-measurement methods known.

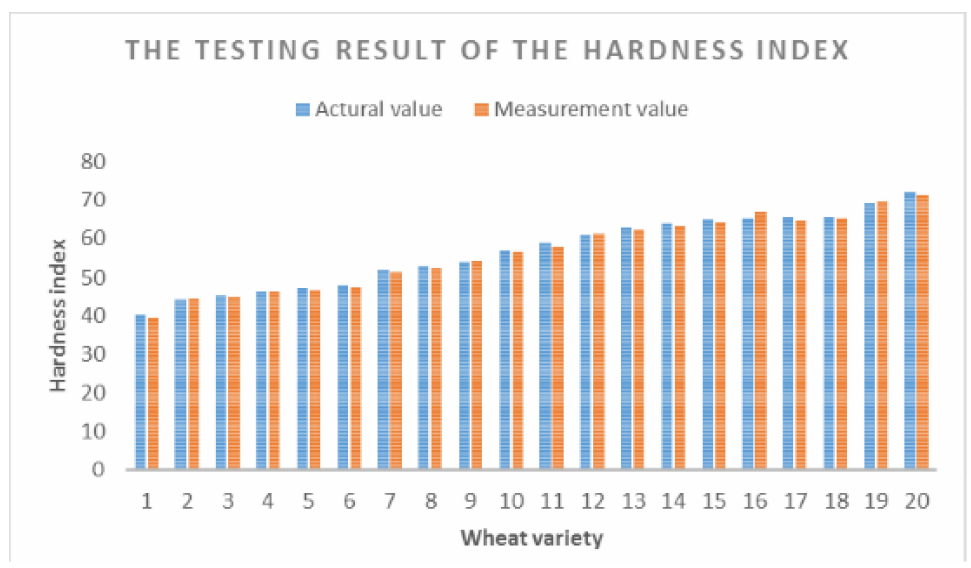

Fig. 11. Measurement results obtained for the wheat hardness. 


\section{Conclusion}

To measure the hardness of wheat, we have developed a new testing method, which is based on the erosion effect of laser light and the corresponding laser-induced ultrasonic signal. The feature parameters of the ultrasonic signal are extracted in both the time and frequency domains, and eight parameters are obtained that correlate the most strongly with the hardness index. Using these characteristics, along with the ELM algorithm and the results for the hardness obtained with the test samples, we have built the appropriate testing model. As a result, we have reduced the maximal relative measurement error to about $-3 \%$, while the mean relative error is close to $1 \%$. This meets the main accuracy requirements for testing the wheat hardness in a practical situation. As a result, our approach yields a new kind of accurate, rapid, non-contact and micro-destructive techniques for testing the wheat hardness.

\section{Acknowledgments}

This study has been supported by the Science and Technology Support Project of the State Grain Administration (No. 201413001), the China Scholarship Council (No. 201408410255) and the Natural Science Foundation of Henan Province (No. 162300410062).

\section{References}

1. Hrušková M; Švec I, 2009. Wheat hardness in relation to other quality factors. Czech J. Food Sci. 27: 240-248.

2. Pomeranz Y, Williams PC, 1990. Wheat hardness. Its genetic, structural, and biochemical background, measurement, and significance. in Advances in Cereal Science and Technology, Ed. by Pomeranz Y, 10: 471-544.

3. Anisur Rakhman and Byoung-Kwan Cho, 2016. Assessment of seed quality using nondestructive measurement techniques: A review. Seed Sci. Res. 26: 285-305.

4. DongshengGuo, Qibing Zhu, Min Huang, Ya Guo, Jianwei Qin, 2017. Model updating for the classification of different varieties of maize seeds from different years by hyperspectral imaging coupled with a pre-labeling method. Computers and Electronics in Agriculture. 142: $1-8$.

5. Stephen R Delwiche, Edward J Souza, Moon S Kim, 2013. Near-infrared hyperspectral imaging for milling quality of soft wheat. Biosystems Engineering. 115:260-273.

6. Nayeli Vélez Rivera, Juan Gómez-Sanchis, Jorge Chanona-Pérez, Juan José Carrasco, Mónica Millán-Giraldo, Delia Lorente, Sergio Cubero, José Blasco, 2014. Early detection of mechanical damage in mango using NIR hyperspectral images and machine learning. Biosyst. Eng. 122: 91-98.

7. Montes JM, Technow F, Bohlinger B, Becker K, 2013. Grain quality determination by means of near infrared spectroscopy in Jatropha Curcas L. Industrial Crops and Products. 43: 301305.

8. Teena MA, Manickavasagan A, Ravikanth L, Jayas DS , 2014. Near infrared (NIR) hyperspectral imaging to classify fungal infected date fruits. J. Stored Products Res. 59: 306-313.

9. Massie D, Slaughter D C, Abbott J. and Hruschka W R, 1993. Acoustic, single-kernel wheat hardness. Trans. ASAE. 36: 1393-1398.

10. Wang W, Wang A, Yang H, 2014. The Wheat hardness acoustic detection method research - based on wavelet transform and discrete cosine transform. Journal of Agricultural Mechanization Research, 6: 10-14. 
11. Agata Marzec, Grazyna Cacak-Pietrzak and Ewa Gondek, 2011. Mechanical and acoustic properties of spring wheat versus its technological quality factors. J. Texture Stud. 42: 319329.

12. Chao Fan, 2015. Early discriminant method of infected kernel based on the erosion effects of laser ultrasonics. Laser Phys. 25: 076101.

13. Chao Fan, Jing-bo Xu, Tie-jun Yang and Hong-Liang Fu 2014. Research on a measurement method for wheat hardness based on the erosion effects of laser ultrasonics. Laser Phys. 24: 046101.

14. Peipei L, Ab W N and Hoon S, 2016. Numerical simulation of damage detection using lasergenerated ultrasound. Ultrasonics. 69: 248-258.

15. Sam Hitchman, Kasper van Wijk and Zoe Davidson, 2016. Monitoring attenuation and the elastic properties of an apple with laser ultrasound. Postharvest Biol. Technol. 121: 71-77.

Fan Chao. 2017. Detection of wheat hardness based on a laser-generated ultrasonic signal. Ukr.J.Phys.Opt. 18: $201-212$

Анотація. Твердість є важливим показником якості пшениці, щуо визначає його використання, иіну та методи обробки пшениці. Тому точні вимірювання твердості ядра $\epsilon$ ключовою проблемою для оцінки якості пшениці. У иій роботі ми запропонували новий метод перевірки твердості пшениці на основі аналізу лазерно-індукованого ультразвукового сигналу. Описані принциии вимірювання, вибірка та попередня обробка ультразвукових сигналів. Акустичний сигнал аналізується, як в часовому так $i$ 6 частотному вимірах $з$ використанням ивидкого дискретного Фур'є та вейвлет перетворення. Основні вісім параметрів, коефічієнти корелящії яких перевищують порогові значення 0,8, вибирались як характеристичні параметри твердості. Вони включали в себе показник сигналу T6, коефічієнт імпульсу T7, співвідночення енергії піддіапазону SER1-SER3, суму величин дискретного Фур'є перетворення та два вейвлет-параметри WTF1 ma WTF2. Модель тестування твердості була побудована на базі алгоритму стандартного екстремального навчання з використанням всіх циих параметрів як вхідних даних. Експерименти виконано з двадиятьма різновидами пшениці з різними показниками твердості. Результати свідчать, щзо максимальна відносна похибка вимірювань та середня відносна похибка є приблизно рівними 3\% і 1\%, відповідно. Як наслідок, наш метод вимірювання твердості пиениці, який базується на комбінації лазерно-індукованих ультразвукових хвиль та стандартного екстремального навчання, є здійсненним та достатньо точним. 